\title{
Women's experience of ageing with a chronic condition
}

\author{
Lynne S. Giddings, Dianne E. Roy \& Elizabeth Predeger
}

\begin{abstract}
Title. Women's experience of ageing with a chronic condition

Aim. This paper is a report of a study to explore the experiences of 'almost old' women as they grow older while living with a chronic condition.

Background. Little is known about the contextual effects of ageing and how it shapes and is shaped by a woman's chronic illness experience. Nurses' understanding of this phenomenon can have positive effects on how their client accesses and responds to healthcare.

Method. Seven women aged between 50 and 58 years participated in this interpretive descriptive study that explored the issues of ageing with a chronic condition. Three focus groups were held between March 2003 and March 2004. Transcriptions were analyzed after each focus group. Participants were given the opportunity to respond to the findings as the analysis progressed.

Findings. The experience of living with a chronic illness foreshadowed what was to come with ageing and embodied the ageing process: it was just part of their lives. Alongside this, the women now felt less out of place. Their peers were catching up and beginning to experience aspects of participants' everyday reality. The women, however, experienced double jeopardy because ageing amplified the ongoing vulnerabilities of living with a chronic condition.

Conclusion. Nurses who recognize the resourcefulness and expertise of women who live with a chronic condition can effectively be co-strategists in their helping them to age well.
\end{abstract}

Keywords: chronic illness, focus groups, nurse-patient relationships, qualitative approaches, women's health

\section{Introduction}

Women in many parts of the world are now living longer and so are more prone to develop a chronic illness (chronic during their lifetime (Rantz et al. 2000, Ministry of Health 2002, Smith et al. 2002, Rice \& Fineman 2003). The World Health Organization's mandate to promote health globally includes improving the wellbeing of those living with chronic conditions (World Health Organisation 2004). In this paper, we report the findings of an interpretive descriptive study that explored the topic of women ageing with chronic conditions in Aotearoa New Zealand.

\section{Background}

Since the 1970s there has been a developing body of literature on women with chronic illness (Koch et al. 2004, Kralik 2002, Loveys 1990, Paterson 2001). Similarly, research studies have highlighted issues relating to women and menopause and other social, psychological effects of ageing (Ebersole \& Hess 1998, Zandi et al. 2002, Smith 2005). Little is known, however, about the ways in which ageing can shape and be shaped by a woman's experience of living with a chronic condition. For many women, the process of transition into ageing, the physiological changes and associated socioeconomic factors they experience, compound an already challenging and sometimes burdensome experience (Thorne \& Paterson 1998). Paterson (2001) has proposed that living with a chronic illness is a continually shifting process and does not follow a chronological trajectory.

Research with older women has drawn attention to the effects of co-morbidity (Yancik et al. 2001) and multiple, often overlapping symptoms caused by co-morbid chronic health conditions (Heidrich et al. 2006) on physical function and quality of life. A recent study by Kralik (2002) described the transition experience of women in midlife (30-50 years) who live with a chronic illness. They transit, she argues, 
from an 'extraordinary' phase of 'turmoil and distress' to incorporating chronic illness in their lives - a phase she called 'ordinariness' (p. 149). Self-esteem, Kralik argued, enabled women to move beyond the boundaries of their identity as a woman with a chronic illness. The women may progress into the extraordinary phase if they are under financial pressure or they develop another illness. MartinMcDonald and Rogers-Clark (2005) support Kralik's position, and argue that the diversity of experiences and the variability of timeframes for people diagnosed with a chronic illness places constraints on generalizing these experiences and describing them in terms of a common pathway through illness. The context of a person's life appears to be more influential on transitional phases than age or type of chronic condition. By studying women within bounded age groups, the age-related contextual factors are more likely to be identified. In this study, we explored the experiences of an age group rarely studied, 'almost old' women (50-65 years), asking how these women who live with a chronic illness incorporate and adapt to the processes of ageing.

For the purposes of the study, we defined 'ageing' as the process of getting older, incorporating biological, physiological, social, cultural and economic changes. A ‘chronic condition' or 'chronic illness' is any physical condition or disease process that persists for a long period of time and often for the remainder of an individual's lifetime (Anderson et al. 1998).

\section{The study}

\section{Aim}

The aim of this study was to explore experiences of 'almost old' women as they grow older while living with a chronic condition.

\section{Design}

This study was based on the viewpoint that women's health is best understood by examining their experiences within a particular context. The research process was guided by the principle of establishing non-exploitative relationships (Timmerman 1999) within research. An interpretive descriptive methodology (Thorne et al. 1997, 2004) facilitated the uncovering of shared meanings of the phenomenon as represented in the women's stories and as interpreted by us.

\section{Participants}

The participants were women aged between 50 and 65 years who self-identified as living with a chronic condition. No exclusion criteria were applied. Participants responded to advertising brochures available though local support networks $(n=4)$. A researcher was also a participant. Snowball sampling added two more participants, making a total of seven. Participants had lived with their conditions for 5-30 years. These included rheumatoid arthritis, chronic back pain and neurological/neuromuscular conditions such as multiple sclerosis and Parkinson's. The women's ages ranged between 50 and 58 years.

\section{Data collection}

The study was conducted in a private room in an educational institution in Aotearoa New Zealand. Seating arrangements were made to enable each woman's comfort. An oval table facilitated visual contact and non-verbal communication.

A three-focus group series was carried out between March 2003 and March 2004. Interaction triggered women's memories, opened up discussion (Webb \& Kevern 2001) and ensured in-depth descriptions of their experience (Krueger 1994) (Table 1).

Focus groups 1 and 2 were facilitated by two researchers. The third researcher, who lives with a chronic condition, responded primarily as a participant. This dual role was discussed prior to gaining participants' consent. One facilitator was unable to attend the third focus group, which necessitated the researcher/participant's involvement in facilitation. Although this dual positioning may have inhibited personal disclosure, it was appropriate as discussion in this third group was primarily focused on preliminary findings. 
Table 1 - The three-focus group data collection and analysis methods

\begin{tabular}{|llll|}
\hline Focus groups & Duration & Participants & Facilitators \\
\hline $\begin{array}{l}\text { Focus group 1 } \\
\text { (March 2003) }\end{array}$ & 90 minutes & 7 & 3 \\
$\begin{array}{l}\text { Focus group 2 } \\
\text { (April 2003) }\end{array}$ & 120 minutes & 7 & 3 \\
$\begin{array}{l}\text { Focus group 3 } \\
\text { (March 2004) }\end{array}$ & 160 minutes & 6 & 2 \\
\hline
\end{tabular}

The first focus group ( 90 minutes) enabled establishment of rapport between the women and the researchers and agreement to appropriate ground rules (e.g. confidentiality issues) and processes. General questions guided the discussion. These included: Tell us your thoughts about being your age and living with a chronic condition? Do you have particular concerns about ageing and living with a chronic condition?

The second focus group (120 minutes), held 2 weeks later, explored some of the issues raised during the first. These included dealing with physical and social isolation, planning for the future, and relationships with health professionals. Some of the women brought with them artistic impressions of their experience. These works created lively discussion, laughter and tears, and moments of deep personal reflection.

After in-depth analysis of data from the first two focus groups, we were left with questions that intrigued us and challenged some of our assumptions. We decided to convene a third focus group (160 minutes) and share with the participants our preliminary interpretive description. The time lapse of 11 months brought an intensity and clarity to their discussion. The women told us that they had often thought about their previous conversations and were delighted to have the opportunity to meet again. They engaged immediately in conversation and shared very personal experiences not touched on in the first focus groups, for example, about sexual relationships, financial situations and other personal stories. Although their responses gave validity to our preliminary findings, they also contributed to a shift in our thinking that enabled a more in-depth and theoretical interpretation.

Finally, we took our findings to an 'expert group' consisting of two nurses with research and clinical expertise. They were aged 50-65 years, female, and lived with chronic conditions including chronic back pain and osteoarthritis. We convened this group as a way to affirm whether or not our processes had been robust and to open our interpretation to critique. We were not disappointed. Although their feedback did extend and reaffirm our broad theoretical interpretation, several constructs were renegotiated and repositioned. We agree with Thorne et al. (2004) that to pass this 'thoughtful clinician test' generates 'more credible findings' (p. 17). During the preparation of this manuscript, drafts were sent to the 'expert group' and the participants, and changes made accordingly.

\section{Ethical considerations}

The study was approved by a university ethics committee. Informed consent to participate was obtained from all study participants at the first focus group. Amendments to the original ethics approval were received in March and September 2004 when it was decided to convene a third focus group and seek further validity of the findings by consulting nurse professionals.

\section{Data analysis}

The focus group tape recordings were fully transcribed. A broad interpretive analysis of data was completed after the first group to provide direction for the second group. To ensure a rigorous analytical process, the original analysis was then put aside and combined data from the focus groups 
analysed using Thorne's et al. (1997) thematic interpretive process. The guiding questions were, 'What is happening here?' and 'What is this telling us about ageing with a chronic condition?' We resisted conceptualizing into broad themes too early. We checked our process with another experienced interpretive researcher to enhance the credibility of our findings. At this point, we engaged in dialectic between the developing theoretical concepts and the data. Conceptual themes vied for prominence. For example, themes of 'catching up', ‘joining my world' and 'feeling less out of place' were at some stage subthemes of each other (Table 2). The third focus group and the clinician feedback helped clarify these relationships. Our process reflects the rigour necessary to ensure the plausibility of the findings (Koch \& Harrington 1998).

Table 2 Themes and subthemes

Central theme: foreshadowing ageing

Theme 1: embodied way of being in the world Subtheme: ageing was matter-of-fact Subtheme: what matters most

Theme 2: foreshadowing ageing Subtheme: dress rehearsal for ageing Subtheme: already grieved the loss

Theme 3: feeling less out of place Subtheme: catching up Subtheme: joining my world Subtheme: understanding of my world

Theme 4: living in the moment Subtheme: living for the day Subtheme: making the most of the moment

Theme 5: risk of double whammy

Theme 6: ongoing vulnerabilities Subtheme: employment and financial issues Subtheme: concerns for the future Subtheme: relationships with healthcare professionals Subtheme: taking care of oneself

\section{Findings}

The findings reflect the experiences of the seven women ageing with a chronic condition.

Foreshadowing ageing was the central theme that emerged: through living with a chronic condition the women in this study were ready for many of the changes that occur as one grows older. They had already experienced changes in physical functioning and appearance and had lived as though older than their chronological years, foreshadowing what was to come. The readiness created was not intentional: they did not do anything to prepare for it, but rather it just happened as part of living with a chronic condition. It enabled a way of being in the world that embodied the ageing process - it was just part of their lives. It was as if it was a 'dress rehearsal for ageing', yet a rehearsal that they 'found themselves in' rather than intentionally choosing. Alongside this, the women described how, through growing older and being in their 50s, they now felt 'less out of place'. Their peers were 'catching up' and beginning to experience aspects of the same everyday reality. The women, however, were at double jeopardy (expressed colloquially below by participants as 'a double whammy') when ageing amplfied the ongoing vulnerabilities of living with a chronic condition. Although ageing was at times in the forefront of their lives, it was mostly just part of their everyday world. 


\title{
Embodied way of being in the world
}

For our participants, 'ageing was matter-of-fact' rather than not being a topic for interested discussion. One participant commented, 'You would not see a woman with a chronic condition writing a book on menopause'. The other women laughed in agreement. This response captured the place of ageing in the women's perceptions of 'What matters most': ageing is notfirst on the list, but is a taken for granted reality. For example, when we attempted to revisit comments that had been made by the women about ageing, they gently but firmly turned the conversation back to issues of their concern, such as financial matters and relationships with healthcare professionals. This apparent 'disinterest' continued across all focus groups. When we presented the preliminary interpretive description, the women looked, nodded, made one or two pleasant comments, and continued with their conversation. Although thefindings were 'not surprising' to them, we were surprised at their reactions. Paradoxically, however, their response affirmed our findings.

The embodiment of ageing also became apparent in how the women positioned themselves in relation to their chronic condition. This was the reference point for their interpreting life changes. What other women might associate with the ageing process, these women relatedfirst to their chronic condition:

\begin{abstract}
It can be hard separating out what is and what isn't a part of your condition. As I am getting older and going through menopause and I get memory lapses (laughter)...Yes, everyone talks about it but I think, when you've got a condition in your brain like I have, a degenerating thing, you think, 'Oh! What's happening?’ Then I realise it isn’t anything to do with my disability or the degeneration of my brain. I now have a saying: 'That wasn't a Parkinson's moment'.
\end{abstract}

\section{Foreshadowing ageing}

The women considered ageing 'inevitable': 'I don't think about it' and 'It's just there all the time.' They were ready for ageing as their experiences of living with a chronic condition 'foreshadowed' what was to come: they were growing older. They knew 'old age', for they already manifested some of the physical, emotional, cognitive and social changes usually associated with getting older:

We suffer a lot of loss, like things that we can't do. You can't bend down and get into your cupboards, or whatever. We have learned to cope with that, we have no choice....We learn.

They were prepared for it: 'I think that in comparison to my friends I've had some preparation they haven't.' Although these experiences can be seen as a 'dress rehearsal for ageing', they formed the fabric of the women's lives. They already knew what it is like to be fatigued and experience decreased mobility, pain and stiffness:

When you are in terrible pain with rheumatoid arthritis, it's like you've broken every limb in your body. You can't lift up anything, you can't walk, and I've been there - it's horrible.

It also required depending on others: 'When I go out now I have to have someone to help me, like in getting up a few steps.' Everyday the women faced the limitations of their human condition: not being able to turn on a tap, roll over in bed, climb a hill or freely lift their 2-year-old grandchild. They had 'already grieved the loss' of social spontaneity as their activities often require preplanning, thorough organization, and frequently the assistance of others. They knew the loneliness that could come from the change in social networks that isolated them from peers and social activities such as 'dancing the night fantastic' or going away for weekend excursions:

I am on my own and have been for 5 years. How do you explain if you meet a new partner - 'Well be careful, I can't swing from the chandeliers'? A couple of hips, a new knee and a few other bits and pieces have been replaced, so that's a bit of an issue.

Their bodies already limited the social and physical activities taken-for-granted in youth and the middle years. When someone complained about 'getting older', the women all agreed that they had 'been there and done that'. In this sense, their ageing peers were 'catching up'; concomitantly, the women felt 'less out of place'. 


\section{Feeling less out of place}

The women reported that many times in the past they had felt 'out of place':

It's very hard when, as a 20 year old, people used to say to me, 'You are too young to have arthritis'. The worst part is that I am actually getting to the age where I am nearly old enough to have it and I've had to cope with it all that time.

Now in their 50s, their peers were 'catching up':

I find now that my peer group is catching up to me. I find my girlfriends saying, 'I can't do this' or 'I've got that'....and I think - 'join my world'.

They fitted in better and their differences were now not so different:

What's happened in the last couple of years is that a lot of people I have worked alongside have been in a similar age group, late 40s into their 50s. What I have noticed is that we have some things in common. They all seem to be talking about having less stamina, having worries about ageing families and for some, parents. And that is not a negative; that is a fact of life. That has helped me feel less isolated within my age group.

The women remarked that often, for the first time, their peers were glimpsing something of their world. 'Understanding of my world' was also evident when family, friends or colleagues experienced an acute illness:

My daughter broke her leg and was in a tremendous amount of pain. She said to me, 'Mum, you are the only person who can really understand what I am feeling. I now relate to some of the pain you have with your arthritis, which I never did before'. People sympathise but they don't really understand unless they've been through something.

Paradoxically, although encouraged by peers' 'catching up', participants were acutely aware of their seemingly accelerated ageing. They too were 'catching up' with their elders: 'I had my father to stay a few weeks back and I realized I was getting up from a chair as slow as he was!' The women glimpsed what may be before them, often fearfully rejecting such thoughts that challenged their hopes for the future.

\section{Living in the moment}

The future was viewed by the women as something always there but which, when glimpsed, challenged their 'living in the moment':

I guess [the future] is a fear, but a fear that I don't think about and I don't want to think to about. I don't dwell on it because I might not get there. So I may as well live and enjoy today and make the best of everyday.

Fear of the future diminished their hopefulness for what could be. Dwelling, even for a moment, on the inevitability of ageing with a chronic condition took these women to a place of hopelessness. Such glimpses were quickly rejected:

I don’t think about the future. I try not to think about the future. I live each day in each day...It's not denial, though, it's survival. We cut off to learn how to cope, it's survival instinct to help keep us going each day.

Although the women asserted the importance of 'living for the day' and 'making the most of the moment', they appeared ready for the possibility of a 'double whammy'. 'Double whammy' incorporates a number of combined effects of ageing with a chronic condition. We use the term to describe when an apparently unrelated event, such as changing socioeconomic status or another illness, combine with the effects of a chronic condition to overwhelm their readiness for ageing.

\section{Risk of 'double whammy'}

All the women told stories of when they felt defeated, unable to cope or 'hit rock bottom' when faced with yet another challenge. These seemed to be the times when ageing and living with their chronic condition coalesced: 
At this stage in my life I couldn't manage working a full day...My rheumatoid (arthritis) is out of remission, so it's very hard to cope with everything. I've had some vicious attacks where I've just had to go to bed...you just don't cope as well. The stress of not having money. What are we going to do? It just all adds up.

The women remained vulnerable to the processes of their chronic condition and to the processes of ageing. Both were ongoing.

\section{Ongoing vulnerabilities}

'Ongoing vulnerabilities' contributed to the risk of women experiencing a 'double whammy.' They included the 'tenuousness of relationships' with health professionals, exacerbation of their condition, and unexpected illnesses or other threats to health. It was, however, employment andfinancial issues that dominated conversation:

You are left with a condition that is degenerating and wonder how are you going to be in retirement. If you think about the money and superannuation and all those issues, we have got them all. We have to provide for our future while in the present.

Employment and financial issues

Seeking or maintaining full-time employment was deemed a problem. From early in their adult lives, for various reasons related to their chronic conditions, the majority of women had faced financial insecurity. Only one participant maintained full-time employment and continuous financial inde pendence; the others had been reliant on family or government support at times. Servicing a mortgage or financing anything beyond basic necessities became difficult, if not impossible. The emphasis on saving for retirement was burdensome, and one woman noted: 'I can hardly pay for the mortgage let alone save for retirement'. They spoke of their 'concerns for the future' as they watched their peers improve financially, while they struggled:

With my peer group, I've watched their lives improve financially...I have not made the big improvements that they have been able to make. I don't travel as much or wear the beautiful clothes that they can afford to go out and buy.

Their struggle was not just with the challenge of illness, but with other losses, such asfinancial security, that rippled out from their incapacities and left them open to the 'double whammy'.

\section{Relationships with healthcare professionals}

Another vulnerability the women identified was the ageing of their healthcare professionals. Most had established effective long-term relationships:

I've had 32-years experience, so that's a good start with the health professionals. I've known [my specialist] for years. If I really need to see him, he will see me immediately. He knows (that) if I say I really need to see him, I do.

The women worked hard to 'hold on' to their caregivers - including medical specialists, general practitioners, and primary healthcare nurses. The thought of having to establish new professional relationships, which often involved 'educating them' to their particular way of living with their chronic condition, was a cause for concern and a potential for a 'double whammy'. This concern was exacerbated by an awareness of their possible need for increased health care as they aged. Alongside this, the women saw the very real likelihood that government health expenditure would shrink: 'The pot getting smaller'. They reflected: 'What will that mean for me?' To this end, they were vigilant in their self-care.

\section{Taking care of oneself}

Knowing the possibilities of an exacerbation of their condition and the occurrence of other illnesses, participants not only attended specialist care but also other health practitioners in an effort to enhance and monitor their health. These included nurse practitioners, acupuncturists, herbalists, osteopaths, chiropractors and massage therapists. This was their way of avoiding the 'double whammy'. They also reported having regular primary healthcare screening, including mammography and bone densitometry. Regular health checks for dental caries and cardiovascular conditions were their norm. Their vigilance was also evidenced in the way they monitored changes in their emotional and mental wellbeing: 
I think I have as many health checks as other people do, mammograms and such...my friends and I are probably equally interested in that, but maybe for different reasons. Because part of my thing is (that) I don't want to have anything else. I don't want to get a cancer or I don't want to get whatever. I'm thinking (that) I don't want anything on top of what I already have, and so I think maybe the motivation behind it is somewhat different.

By maximizing their health, the women were reassured that, 'I am very well, the rest of me isfine'. This self-awareness and monitoring went hand-in-hand with a knowing of 'what matters most' in their lives: 'Don't sweat the small stuff'.

\section{Discussion}

The use of three focus groups and ongoing interpretive analyses were strengths of this study. This approach added a richness and depth to the interpretation of the women's experiences of ageing with a chronic condition. The limitation of numbers was offset by the comprehensive nature of processes used. Transferability was further supported by the variety of diagnoses represented in the participants. A limitation of the study was the participants' cultural homogeneity. They were primarily Pakeha (European) and identified as middle-class. The findings, therefore, may not be transferable to nonEuropean women or women in other socioeconomic positions. It is also acknowledged that life expectancy, severity of disability, length of time living with a condition and age at onset, could play a part in how the women responded. These issues could usefully be explored through methodologies that would uncover the influence of such contextual factors.

There is little literature on ageing with a chronic condition, and our study broke new ground by focusing on 'ageing' rather than 'living' with a chronic condition. Ourfindings are complementary, however, to theoretical developments within chronic illness research. For example, Kralik (2002) identified mid-life women's ‘quest for ordinariness' in living with a chronic condition. Ordinariness meant reconstructing life with illness as a transition that is non-linear and sometimes cyclical. Our notion of 'foreshadowing ageing' not only complements Kralik's theoretical position, but extends it to incorporate the process of ageing with a chronic condition. As participants transited through their 'almost old' years they reconstructed their experience, so that ageing was integrated as part of the 'everyday' and was embodied.

Ageing was for the most part, matter-of-fact. Glimpses of the future, however, challenged this embodiment as ageing processes created the ever-present possibility of a double whammy. Consistent with the findings of Iaquinta and Larrabee (2004), we found that women 'lived for the day' and 'made the most of the moment', thereby enabling them to face their future. They recognized that 'this might be as good as it gets'. Although this behaviour has often been interpreted by healthcare professionals as denial (Martz 2004), we argue that it is a process of surviving in the moment. Rather than not taking seriously the realities of ongoing chronicity and ageing, these women remained very aware of their vulnerabilities, and their ageing was 'foreshadowed' in the everydayness of their lives. Although inevitable, ageing was tempered by their commitment to remain healthy. Added to this, they remained connected to their social networks of support, valued their relationships with family, friends and healthcare professionals, and learned how to 'live in the moment' and to live on less. This connectedness with others has also been documented by Predeger and Mumma (2004).

The women's readiness for ageing came from having already encountered some of the changes that occur with ageing. They knew well the arduous nature of ongoing tiredness and fatigue, decreased mobility, pain and loneliness. They already knew how to navigate the healthcare system and the healthcare professionals within it (Iaquinta \& Larrabee 2004). Their knowing came from experience, but it came at a cost. They had to live with the paradox of hopefulness and vulnerability. As they 'lived in the moment', they were ever conscious of the tenuous nature of their health status: the 'double whammy' always just around the corner.

Having a chronic condition did not provide insurance from the possibility of having other age-related diseases (Seeman et al. 1989), it was an ever-present reality for these women. They knew they were equally at risk as their peers for developing conditions such as osteoarthritis and cancer. 
Conscious of the possibility of a 'double whammy', participants reported that they were vigilant in preventive care, especially screening and self-monitoring. This finding contrasts with Nosek and Howland (1997) who reported that women with severe disabilities were less likely to receive pelvic examinations. The difference here is that their sample group were women whose disabilities made accessibility problematic. Our participants, although differently-abled, would not be classified as having 'severe' disabilities and they had strategies in place that enabled continuing vigilance in preventive care.

Paradoxically, it was the strategies developed through living with a chronic condition that enabled their readiness to deal with double whammies. When faced with a challenge to their health status, they were thrown not so much into the 'deep end' as into the 'shallow end'.

The women's balancing of their need for dependence and independence was critical to sustaining hopefulness in the face of everyday realities. They knew when to be dependent so that they could maintain their independence. Toombs (2004) argues that 'giving-up in one area might well free [a person] to embrace other important areas of life' (p. 646). Rather than the rehabilitation model of binary opposites (dependence versus independence), we argue that they are in a dialectical relationship. Dependence and independence are complementary, creating a synthesis that contains both rather than being either/or. As Sherrard (1996) suggests, 'We would be better off if healthy people [living with a chronic condition or disability] could be understood as being both dependent and independent in different ways, and that neither polarity is considered good or bad' (p. 129). What is created is a third position, in which dependence enables independence. Our participants' stories revealed how often they made decisions to receive assistance, not because they could not do what was required, but rather so that they could have the time and energy to do something else that mattered more.

\section{Implications for nursing practice}

Ageing shapes and is shaped by a person's chronic illness experience. This has implications for nurses’ relationships with clients who live with a chronic condition. If nurses are aware of the nexus between ageing and living with a chronic condition, they are better prepared to assist when their clients are faced with a double whammy. More critical to effective management, however, is awareness that their clients already have strategies at hand and have self-knowing and expertise in living with their chronic condition. Finding the fine balance between stepping in and holding back in offering care requires nurses to know their clients in context. This balance can only be achieved by establishing processes of negotiation, with two-way communication within an ongoing therapeutic relationship that is mutually respectful of each other's expertise (Koch et al. 2004, Toombs 2004). Such a relationship, which enhances the client's highly tuned knowing of themselves, can make the difference between effective and ineffective care.

\section{Conclusion}

The importance of ongoing relationships within a primary care context cannot be over-emphasized. Although this study may be limited by cultural specificity and a small purposive sample, the women's stories highlight the pivotal nature of these relationships. When effective, they can contribute to a client's efforts to age well while living with a chronic condition. Every new healthcare professional/client relationship requires time for the partners to get to know each other. For the most part, both are in it for the 'long haul'.

\section{Acknowledgements}

A special thanks to seven courageous women who so willingly shared their stories, their laughter and their tears. Everyday they face the challenge of living fully in the moment while confronting their own fears and often the prejudiced fears of others.

\section{Author contributions}

LG and EP were responsible for the study conception and design and LG and DR were responsible for the drafting of the manuscript. LG, DR and EP performed the data collection and LG and DR 
performed the data analysis. LG obtained funding and LG and DR provided administrative support. LG and DR made critical revisions to the paper.

\section{References}

Anderson K., Anderson L.E. \& Glanze W.D. (Eds). (1998). Mosby’s Medical, Nursing, and Allied Health Dictionary. Mosby, St Louis, MO.

Ebersole P. \& Hess P. (1998). Aging Today: Toward Healthy Aging (5th edn). Mosby, St Louis, MI.

Heidrich S.M., Egan J.J., Hengudomsub P. \& Randolph S.M. (2006). Symptoms, symptom beliefs, and quality of life of older breast cancer survivors: a comparative study. Oncology Nursing Forum 33(2), 315-322.

Iaquinta M.L. \& Larrabee J.H. (2004). Phenomenological lived experience of patients with rheumatoid arthritis. Journal of Nursing Care Quality 19(3), 280-289.

Koch T. \& Harrington A. (1998). Reconceptualizing rigour: the case for reflexivity. Journal of Advanced Nursing 28(4), 882-890.

Koch T., Jenkin P. \& Kralik D. (2004). Chronic illness self-management: locating the 'self'. Journal of Advanced Nursing 48(5), 484-492.

Kralik D. (2002). The quest for ordinariness: transition experienced by midlife women living with chronic illness. Journal of Advanced Nursing 39(2), 146-154.

Krueger R.A. (1994). Focus Groups: A Practical Guide for Applied Research (2nd edn). Sage, Thousand Oaks, CA. Loveys B. (1990). Transitions in chronic illness: the at-risk role. Holistic Nursing Practice 4, 56-64.

Martin-McDonald K. \& Rogers-Clark C. (2005). Journeys through illness: suffering and resilience. In Living with Illness: Psychosocial Challenges for Nursing (Rogers-Clark C., Martin-McDonald K. \& McCarthy A., eds), Elsevier, Sydney, pp. 143-159.

Martz E. (2004). Do post-traumatic stress symptoms predict reactions of adaptation to disability after a suddenonset spinal cord injury? International Journal of Rehabilitation Research 27(3), 185-194.

Ministry of Health (2002). Health of Older People Strategy: Health Sector Action to 2010 to Support Positive Ageing. Ministry of Health Publications, Dunedin.

Nosek M. \& Howland C. (1997). Breast and cervical cancer screening among women with physical disabilities. Archives of Physical Medicine and Rehabilitation 78(12), S39-S44.

Paterson B. (2001). The shifting perspectives model of chronic illness. Image: Journal of Nursing Scholarship 33, 21-26.

Predeger E. \& Mumma C. (2004). Connectedness in chronic illness: women’s journeys. International Journal for Human Caring 8(1), 13-19.

Rantz M.J., Dorman-Marek K. \& Zwygart-Stauffacher M. (2000). The future of long-term care for the chronically ill. Nursing Administration Quarterly (Fall) 25(1), 51-58.

Rice D.P. \& Fineman N. (2003). Economic implications of increased longevity in the United States. Annual Review of Public Health 25, 457-473.

Seeman T.E., Guralnik J.M., Kaplan G.A., Knudson L. \& Cohen R. (1989). The health consequences of multiple morbidity in the elderly. The Alameda County study. Journal Of Aging And Health 1, 50-66.

Sherrard I. (1996). Living with a Damaged Body. Unpublished masters dissertation, Massey University, Palmerston North, New Zealand.

Smith P.E. (2005). Menopause: assessment, treatment, and patient education. Nurse Practitioner: American Journal of Primary Health Care 30(2), 32-40.

Smith J., Borchelt M., Maier H. \& Jopp D. (2002). Health and wellbeing in the young old and oldest old. Journal of Social Issues 58(4), 715-732.

Thorne S. \& Paterson B. (1998). Shifting images of chronic illness. Image: Journal of Nursing Scholarship 30(2), 173-178.

Thorne S., Reimer-Kirkham S. \& MacDonald-Emes J. (1997). Interpretive description: A non-categorical qualitative alternative for developing nursing knowledge. Research in Nursing and Health 20, 169-177.

Thorne S., Reimer-Kirkham S. \& O’Flynn-Magee K. (2004). The analytic challenge of interpretive description. International Journal of Qualitative Methods 3(1), Retrieved from http://www.ualberta.ca/_iiqm/backissues/3_1/pdf/thorneetal.pdf on 8 June 2005

Timmerman G.M. (1999). Using a women's health perspective to guide decisions in quantitative research. Journal of Advanced Nursing 30(3), 640-645.

Toombs S.K. (2004). 'Is she experiencing any pain?': disability and the physician-patient relationship. Internal Medicine Journal 34, 645-647.

Webb C. \& Kevern J. (2001). Focus groups as research method: a critique of some aspects of their use in nursing research. Journal of Advanced Nursing 33(6), 798-805.

World Health Organisation (2004) Health and Human Rights. Retrieved from http://www.who.int/hhr/en/ on 27 November 2004. 
Yancik R., Wesley M.N., Ries L.A.G., Havlik R.J., Edwards B.K. \& Yates J.W. (2001). Effect of age and comorbidity in postmenopausal breast cancer patients aged 55 years and older. JAMA: Journal of the American Medical Association 285, 885-892.

Zandi P.P., Carlson M.C., Plassman B.L., Welsh-Bohmer K.A., Mayer L.S., Steffens D.C. \& Breitner J.C.S. (2002). Hormone replacement therapy and incidence of Alzheimer disease in older women: the Cache County Study. JAMA: Journal of the American Medical Association 288, 2123-2129. 